\title{
Resource-sharing Construction of Area E-government Information Based on Cloud- computing
}

\author{
Taking Hebei Cangzhou as an Example
}

\author{
Linna Huang \\ Department of Computer Engineering \\ Cangzhou Normal University \\ Cangzhou, Hebei, China \\ Hln0322@163.com
}

\author{
Baoguo $\mathrm{Gu}$ \\ Cangzhou Finance and Economics School \\ Cangzhou, Hebei, China \\ Czcjxx666@163.com
}

\begin{abstract}
Cloud computing, with superior computing power, low-cost and high-security, will be applied to the resourcesharing area of E-government information with great significance and value. From the point of theory, technology and practice, it is scientifically feasible to build a cloud-based E-government information resource-sharing platform, and some areas are actively building this. This paper, through analysis of the problems existing in Cangzhou E-Government and through the design of the E-government cloud computing model, puts forward new ways to explore the development of regional E-government based on cloud computing.
\end{abstract}

Keywords- E-government; information resources; sharing; Cangzhou City

\section{INTRODUCTION}

With the development of computer technology, network technology and communication technology, informatization promotes, as a productivity, all aspects of society and economy to undergo profound changes. And E-government informatization has become not only an important means to drive the government management system, but also a bridge of communication for the government and the people.

Although the Chinese government attaches great importance to the construction of government information, but in general, the information infrastructure is still very weak and seriously lagging behind the development and utilization of information resources. The level of digitization and sharing of information is very low with less information openness, timeliness, comprehensiveness. The government information systems developed at all levels of government are various without unified data scale, standard and format. Therefore, to promote the process of E-government, how to solve the sharing of information resources has become an urgent task.

\section{THE CURRENT PROBLEMS EXISTING IN CANGZHOU E- GOVERNMENT}

(1) Each department is in its own way with low-level redundant construction. Lack of overall planning, organizational coordination mechanism is not yet in place, resulting in the deletion of e-government construction management, which makes each department dispersed to raise funds, do respective construction of low-level redundant construction seriously. In addition, E-government attaches importance to investment in construction projects and neglects the operation and maintenance of applications and systems, resulting in a short-term effect. Most of the Web sites (except a few good ones), for example, scattered in Cangzhou counties (cities, districts) and municipal government departments, have features of non-standard construction, low update frequency, which leads to failure in three functions like open of the government website information, interaction and handling with affaires online, with equipment duplication of investment and a small amount of user access. Some departments' (units') website can't be updated for a long time, which results in bad impact of the government's image in public mind.

(2) There are no unified construction standards with difficulties of interoperability and resource sharing. Because of non- unified construction standards, "departmental partition "and" Information Island" are formed. On one hand, this sector urgently needs other departments to provide data while other departments can not provide. And vice versa, For instance, when the family-planning department needs urgently family household registration information of the public security department and the public security departments needs urgently community residents' important information, it is difficult to share a common. Even because of inconsistent statistics caliber and sampling standards, two sets of data are "fighting". This situation leads to difficulties to the social meticulous management. While the horizontal E-government construction is lagging far behind the longitudinal E-government of the management department, with weak "places" and strong "rules".

(3) There is a conflict between the security requirements of the system and the openness of the platform. Most units do not have three security measures or more, like integrated implementation of the CA authentication, data backup, firewall with no other security measures, leading to serious safety hazard.

(4) There is high cost of running the system. Application deployment, operation and maintenance, frequent upgrade and update of the computer and software systems make various departments maintain a dedicated technical team with a lot of funds every year for the upgrade and maintenance of the system, resulting in high running costs. 


\section{Cloud-COMPUTing OF E-GOVERnMENT HAS BECOME THE GENERAL TREND}

The emergence and rapid development of cloud computing make the construction of e-government obtain a new opportunity for the development of e-government applications and a new phase. On one hand, cloud computing, as the representative of a variety of new IT technologies and modes, is gradually applied in the field of e-government widely.The government-informatization department also considers cloud computing as an opportunity of egovernment transformation, hoping, through cloud computing, to consolidate IT resources to promote interoperability, information sharing and business collaboration to fulfill e-government transformation by dealing with fragmented management and dispersed construction. On the other hand, the focus of e-government construction is further inclined to the direction of public service and information sharing. In the process of transformation of government functions from manage model to service model, more and more appealing of "collaborative government" makes "cloud-model” become the best choice.

The core idea of cloud computing, which is a new calculation of the Internet, is to calculate the virtual resources into a resource pool for unified management and scheduling to provide services to the user [1]. In this way, the shared hardware and software resources and information can be like water, electricity and gas to meet the users' demands through their terminal equipments and the matched cloud network, cloud storage, cloud security and cloud management. The nature of cloud computing is an intensive mode to complete high concentration, full sharing, use ondemand. Application of cloud computing makes intensification and platformization of E-government construction develop more evident. Information resourcesharing and government collaboration can be achieved more easily, providing a strong technical support for the development of e-government transformation. On one hand, further association of government data center forms the "administrative cloud" to achieve cross-system information sharing and collaboration of government affairs for further opening up to the society. On the other hand, in some application of government affairs closely related to people's livelihood, cloud computing technology will help accelerate the pace of system construction and improve the application effect.

The "administrative cloud" construction benefits not only the administrative efficiency, but also the public service and improvement of the people's livelihood. Local governments aiming at this goal have been started, like Chengdu City Hall Cloud-computing Center, Tianjin National Digital Publishing Base Cloud-computing Center, Suzhou Industrial Park Administration Cloud-computing Center, Shandong Cloud-computing Center, Wuxi City Cloud-computing Center, Zhenjiang Shenyun Cloud-platform, Guizhou Cloud Computing Networking Center. This also provides the experiences, which we can draw lessons from, for development of Cangzhou E-government “cloud” .

\section{PROBLEMS NEEDED TO BE SOLVED IN CANGZHOU E- GOVERNMENT INFORMATION SHARING AND BUSINESS COLLABORATION}

\section{A. The unity of common application software}

Among three basic services of cloud computing, SaaS should be the final and most important form of service. In the e-government application, this mode can be used for ASS to realize common application software unity. For instance, for all departments of Cangzhou city, their daily office, approval, law enforcement, public information, video conferencing can be unified in the whole city through ASS in order to achieve large-scale applications, a wide range of information sharing and convenient business collaboration. The implementation from OA system online to document information transfer, from online approval to longitudinal linkage transaction can form a unified examination certificate database. Online law enforcement can achieve one- net handling, one-net query and full disclosure, which can be connected with the natural person, the legal person and credit. If these basic common application systems are made by the respective construction and are run independently, there would be no sharing and collaboration.

\section{B. Interconnection, intercommunication and interoperability between application systems}

Another basic service of cloud-computing is PaaS [2], which regards the platform of software development and running platform as a service for the user. It is also referred to PSS. Those non-common sectoral professional application systems can be constructed in this way. In general, the platform includes the server, storage, basic software (operating system, database, middleware, etc.). Sharing of these basic hardware and software facilities can save a large amount of construction and operation cost. But it needs deep solution of information sharing and business collaboration, which is made not only through the basic hardware and software sharing, but also through the interoperability of applications. One method is the development of component group as an important part of the shared platform for each department to develop services of business development system, such as exchange of information, identity authentication, form customization, customization process, information management, demand acceptance, short message service etc. Another is to regard unified common application software as platforms to develop proprietary application systems for the Department through function expansion. For instance, the unified platform of online office, approval and enforcement can be used for construction of the specialized business management systems for many departments.

\section{Data as a platform}

With the deepening and extension of E-government application, comprehensive development and utilization of information resources will become more and more important, more and more valuable. Therefore, the data will become an important platform of E- government to provide services for the government and the society. That is to say, "data as a service" (DaaS) will become the important form of cloud 
services. The data, as a platform, can provide three levels of service. The first is to provide metadata services of various types of basic database like population, legal institutions and spatial geography, as standards of information exchange between departments. That promotes construction of the sharing basis database. The second one is to keep the shared database as a platform to provide basic information and operational service for various departments, improving the quality and efficiency of government operation. The third one is to open E-government to the society to provide conditions of development of public service system for the social institutions which relies on the E-government data. It is also an important development direction of so-called "Egovernment 2.0”,

\section{The establishment of an effective system}

Without doubt, the cloud computing provides better technical conditions for the intensification development of Egovernment. However, it is necessary to establish strong centralized management and integrated system if we want to make cloud computing mode into intensification mode of Egovernment and finally solve the interoperability, information sharing, and business collaboration. Or it is likely to have four kinds of results: (1)Departments compete to build cloud computing center, resulting in a new upsurge of investment construction from previously separate construction and manufacturing "information islands" to manufacturing "information cloud". (2)The construction of a unified cloud computing center solves the problem of intensive technical support. But if it is not coordinated from the business application level, then cloud operation is still some independent system, forming a "cloud island". Then problems of interoperability, information sharing, business collaboration can not be solved. (3) The construction of a unified cloud computing center is made. But if there is no strong integration system, there is no guarantee that a new system of departments are using this cloud, no guarantee that the original system migrates to the cloud, ultimately forming a "waste of cloud". (4) The adoption of the third "cloud service" is made. This is similar to the second one, and is more likely to have "Cloud Island". Therefore, if there is no strong general management of informatization projects to all the city departments, then the inevitable result is that departments respectively ask for cloud services, and this has no fundamental difference with the previous scattered construction.

\section{SHARING-MODE CONSTRUCTION OF E-GOVERNMENT INFORMATION RESOURCES OF CANGZHOU}

\section{A. Guiding ideology}

(1)Arrange all department requirements, unify procurement of cloud computing services, promote government affairs gradually into cloud-computing model and promote the sharing of resources, information sharing and business collaboration. The new E-government framework should possess the following several points: platformization of the basic network, cloudization of application resources and socialization of professional service.

(2)The technical requirements of the E-government platform include: large-scale distributed storage technology, efficient and reliable background system, automatic monitoring technology, information security technology, green energy-saving design in the data center and other core technology. Cloud computing platform can be used for a new generation of cloud computing center of easy management, dynamic efficiency, flexible expansion, stability and reliability, use on-needed, energy-saving and environmentalprotection.

(3) Plan as a whole and implement step-by-step. Plan as a whole according to the future 2-3 years' development trend of the government cloud, then package the current resources , establish relevant application and data center according to the actual situation of the current e-government management from the design, build " cloud " to access the platform, progressively complete the system construction to ensure the steady advance.

\section{B. Cloud-computing model design of E-government}

The system structure of Cangzhou E-government cloud computing model consists of five parts: resource layer, virtual layer, application management layer, business presentation layer and CA Certification Center, as shown in figure 1.

The resource layer [3] at the bottom is the material basis to realize the resource integration and sharing. Cloud computing can be used to integrate the hardware equipments to enhance effectively storage capability of the system and computing power to meet the increasing demands of Egovernment. By integration, the hardware cost can be reduced greatly to realize the rational allocation of social resources. The physical resource layer exists as distributed shared modes, but eventually it is presented to the user as single entities.

The virtual layer includes the virtual server, the virtual memory and the virtual network. Cloud Computing can use virtualization technology to shield the differences of underlying different servers, storage devices, network equipments and realize the heterogeneous support of the storage resources and cyber resources, making the physical facilities of the system into a shared resource pool--computation resource pool, storage resource pool, software resource pool, etc., which makes E-government possess synergistic basis for the work and realizes the quick resource-deployment, distribution on-need and resource isolation. That can improve the utilization rate of resources and balance effectively performance of the E-government cloud-computing system.

The application management layer is the most important layer in the E-government cloud-computing system. This layer, as the backstage management of the system, makes dynamic management resource and supports related businesses of the E-government system, mainly responsible for system capacity planning, resource deployment, surveillance and security. 
The business presentation layer is the function-reflection layer in the E-government cloud-computing system. Egovernment makes this layer not only complete the basic computing and storage business, but also provide all kinds of network services, including online software services and online platform services. A one-stop E-government service platform provides a strong system service for office automation, decision support and knowledge management.

The CA Certification Center provides issuing and management of the digital certificates. It first generates its own key pair, and then makes his "self-signed" certificates, finally transmits them to the resource layer, the virtual layer, the application management layer, the business performance layer and the relevant users to ensure all communications of the user, the business layer, and other layers to be transmitted by public key encryption, in order to prevent information leakage and denied sending behavior.

\section{CONCLUSION}

The current common development characteristics of the global E-government is to improve the openness sharing level of the safely multi-channel data information through intensification construction of public infrastructure and to enhance synergies of the governmental service, so as to provide citizens with holistic E-government services. In our country, with the development of government information, great increase of the government information data and more requirements of E-government affairs, cloud computing [4-5] is bound to play a major role in the future development of electronic government affairs and the E-government construction will also obtain great progress. With the gradual application of cloud computing in E-government, the informatization level of E-government in our country will be elevated to a higher level. The one-stop E -government system based on the cloud platform will bring more convenience and benefit more people.

\section{REFERENCES}

[1] Cloud Computing, http://en.wikipedia.org/wiki/Cloud_computing.

[2] Vaquero M, Rodero L, Caceres J et al., "A Break in the Clouds: Towards a Cloud Definition,” ACM SIGCOMM Computer Communication Review, vol. 39, pp. 50-55, January 2009.

[3] Wu Qiuping, "Application and Research on Cloud Computing in EGovernment System," Computer and Modernization, pp.116-120, July 2011.

[4] Chen Quan, "Cloud Computing and Its Key Technology," Computer Application, vol.29, pp.2562-2567, September 2009.

[5] Liu Peng, Cloud Computing, Beijing: Electronic Industry Press, 2010, pp.1-2.

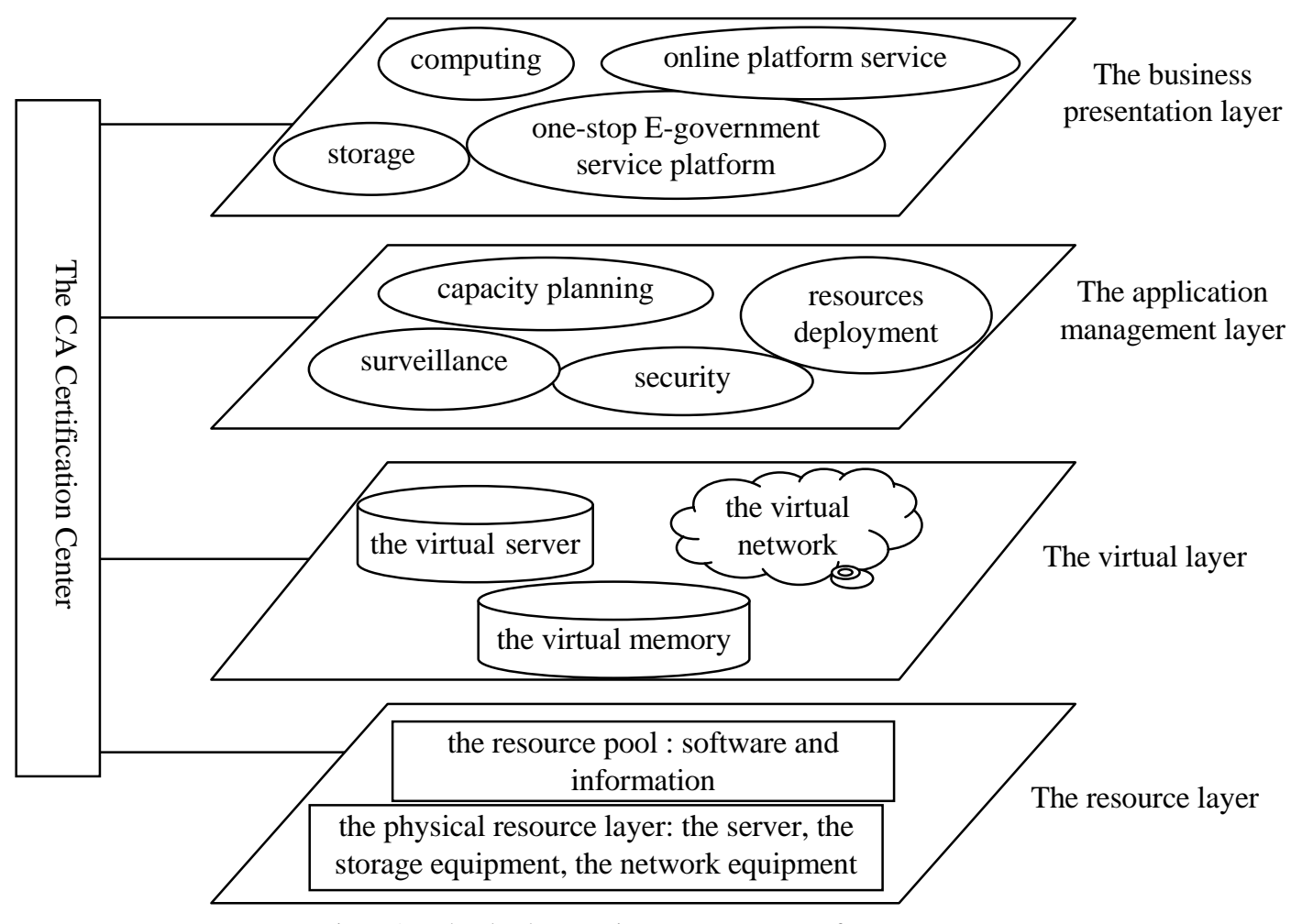

Figure 1. The cloud-computing system structure of E-government 